\title{
AVALIAÇÃO DE DANOS MECÂNICOS EM SEMENTES DE SOJA POR MEIO DA ANÁLISE DE IMAGENS ${ }^{1}$
}

\author{
EBERT PEPE OBANDO FLOR ${ }^{2}$, SILVIO MOURE CICERO ${ }^{3}$, JOSÉ DE BARROS FRANÇA NETO ${ }^{4}$, \\ FRANCISCO CARLOS KRZYZANOWSKI
}

\begin{abstract}
RESUMO - O trabalho teve o objetivo de avaliar a eficiência da utilização da técnica de análise de imagens na identificação de danos mecânicos em sementes de soja e sua relação com a qualidade fisiológica. Como a referida técnica proporciona a análise das sementes sem destruí-las, é possível comprovar, por meio do teste de germinação, quais danos detectados pela análise de imagens são realmente importantes, em função dos prejuízos causados ao processo germinativo. A pesquisa foi conduzida com três cultivares de soja (FT-2, FT-10 e IAC-2), cujas sementes apresentam diferentes teores de lignina no tegumento e diferentes comportamentos quanto à resistência aos danos mecânicos. Os danos mecânicos foram provocados por meio do teste do pêndulo em seis regiões distintas das sementes. Os resultados obtidos indicaram que a análise de imagens permite identificar danos mecânicos externos e internos em sementes de soja; também, permite observar danos por umidade e danos por percevejo.
\end{abstract}

Termos para indexação: Glycine max L., raios-X, germinação.

\section{EVALUATION OF MECHANICAL DAMAGES IN SOYBEAN SEEDS BY IMAGE ANALYSIS}

\begin{abstract}
The present study had the objective of developing a non-conventional method to determine mechanical damage in soybean seeds, and also to verify its relation to the physiological quality, using the image analysis technique. Unlike the traditional tests, this technique analyzes seeds without destroying them, and together with the germination test, it can be observed that the damage detected in the image analysis is really important because of its influence on the germination process. The research was carried out with three cultivars of soybean (FT-2, FT-10 and IAC-2), possessing different contents of lignin in the seed coat (different resistance performance for mechanical damage). The mechanical damage had been caused by means of the pendulum test in six different regions of the seeds. The image analysis identified external and internal mechanical damage in soybean seeds, and was also efficient in detecting weathering and stink-bug damage.
\end{abstract}

Index terms: Glycine max L., X-ray, germination.

\section{INTRODUÇ̃̃O}

Entre as causas responsáveis pela perda da qualidade em sementes de soja, destacam-se os danos mecânicos provocados, principalmente, durante as operações de colheita e beneficiamento. Trincas ou rachaduras situadas superficialmente são facilmente

\footnotetext{
Submetido em 13/07/2003. Aceito para publicação em 12/12/2003. Parte da tese apresentada pelo primeiro autor para obtenção do título de Doutor em Agronomia.

${ }^{2}$ Eng. Agr., Dr., Curso de Pós-Graduação de Fitotecnia, USP-ESALQ, Piracicaba-SP.

${ }^{3}$ Professor Titular, Departamento de Produção Vegetal, USP-ESALQ, Caixa Postal 9, 13418-900, Piracicaba-SP

${ }^{4}$ Eng. Agr., Ph.D., Pesquisador da EMBRAPA- Soja, Caixa Postal 1061, CEP 86001-970, Londrina, PR.
}

detectadas, ao passo que os danos mecânicos internos exigem exames mais detalhados para sua detecção. Não apenas os danos grandes e visíveis, mas também danos menores ou microdanos, mesmo que invisíveis a olho nu, dependendo da sua localização, podem reduzir significativamente a qualidade das sementes.

A semente de soja é muito sensível ao dano mecânico, uma vez que as partes vitais do eixo embrionário (radícula, hipocótilo e plúmula) estão situados sob um tegumento pouco espesso, que praticamente não lhe oferece proteção (França Neto \& Henning, 1984). A susceptibilidade do tegumento da semente ao dano mecânico constitui-se em caráter importante para a qualidade de sementes de soja, a qual está intimamente relacionada com a variabilidade genética (Carbonell, 1991). 
Alvarez (1994) separou sementes de soja dos cultivares FT-2, FT-10 e IAC-2, de acordo ao teor de lignina presente no tegumento, que lhes confere diferentes comportamentos quanto à resistência aos danos mecânicos, sendo o cultivar FT-2 com $6,19 \%$ de lignina (maior resistência), FT-10 com 5,28\% (medianamente resistente) e IAC-2 com 4,21\% (menor resistência). Carbonell \& Krzyzanowski (1995) propuseram o "teste do pêndulo", que através da queda livre de um pêndulo de aço sobre sementes individualizadas em alvéolos de um disco de aço, recebem um impacto de força conhecida; é uma metodologia que pode ser utilizada em programas de melhoramento de soja para caracterizar genótipos quanto à resistência a danos mecânicos. Utilizando a referida metodologia, os autores constataram maior resistência do cultivar FT-2 em relação aos cultivares FT-10 (medianamente resistente) e IAC-2 (pouco resistente).

A utilização da análise de imagens para a determinação de danos mecânicos em sementes destaca-se como uma eficiente ferramenta, pois trata-se de um método de grande precisão (as sementes podem ser examinadas individualmente em imagens ampliadas que poderão indicar, em detalhes, a área danificada, sua extensão e localização) e não destrutivo. Desta maneira, as sementes submetidas à análise podem ser colocadas para germinar e permitir o estabelecimento de relações entre os danos mecânicos e os prejuízos causados à germinação (Cícero et al., 1998). O teste de raios-X, padronizado pela Associação Internacional de Análise de Sementes (ISTA, 1985), baseia-se no princípio da obtenção de imagens com o emprego de raios-X. Ao atravessar as sementes, um feixe de raios-X cria uma imagem permanente dessas sobre um filme. Esta técnica foi inicialmente introduzida na Suécia, na década de 1950, para a avaliação da qualidade de sementes de espécies florestais (Simak \& Gustafsson, 1953), sendo atualmente utilizada como teste de rotina para a avaliação da qualidade de sementes de espécies olerícolas (Liu et al., 1997; Van der Burg et al., 1994).

O método tem sido adotado na avaliação de sementes de Pinus spp (Simak, 1984; Sahlén et al., 1995), milho (Smith \& Grabe, 1985; Carvalho et al., 1999; Cícero et al., 1998; Obando-Flor, 2000), algumas cucurbitáceas (Kamra, 1966; Obando-Flor et al., 2001) e diversas espécies florestais (Swaminathan \& Kamra, 1961; Oliveira, 2000; Machado, 2002). A análise de imagens é, segundo Girardin et al. (1993) e Carvalho et al. (1999), o melhor método não destrutivo para avaliar as características morfológicas internas da semente.

Diante do exposto, este trabalho foi realizado com o intuito de avaliar a eficiência da utilização da técnica de análise de imagens na identificação dos danos mecânicos em sementes de soja e sua relação com a qualidade fisiológica.

\section{MATERIAL E MÉTODOS}

A pesquisa foi conduzida nos Laboratórios de Análise de Imagens e de Análise de Sementes, do Departamento de Produção Vegetal, da Escola Superior de Agricultura "Luiz de Queiroz", Universidade de São Paulo, em Piracicaba, SP, e na Empresa Brasileira de Pesquisa Agropecuária (Embrapa - Soja), em Londrina, PR.

Foram utilizados os cultivares FT-2, FT-10 e IAC-2, cujas sementes apresentam diferentes teores de lignina no tegumento, conferindo-lhes diferentes comportamentos quanto à resistência aos danos mecânicos, de acordo com a classificação de Alvarez (1994).

As sementes para o estudo foram produzidas na Fazenda Santa Terezinha, da EMBRAPA - Soja, em Londrina, PR, na safra 2001/2002. A colheita foi realizada arrancando-se manualmente as plantas, quando as sementes estavam no estádio de maturidade fisiológica (R7). Em seguida, foi retirado o restante das folhas das plantas e penduradas em varal dentro de um armazém ventilado, para perda gradativa de umidade, até atingir o teor de água aproximado de $20 \%$ na semente e, então, foi realizada a trilha manual, para a retirada das sementes dos legumes, visando, assim, propiciar o mínimo de dano mecânico possível às sementes.

Após a trilha, as sementes foram colocadas dentro de sacos de filó para a secagem em um secador estacionário, com ar à temperatura ambiente, até atingir $\mathrm{o}$ teor de água de 13\%. Os valores de umidade foram avaliados com o auxílio de um determinador de umidade digital, marca Burrows.

A uniformização do tamanho das sementes foi efetuada com o auxílio de peneiras, sendo que, para o cultivar IAC-2 utilizaram-se, de forma sobreposta, as peneiras com crivos de 7,0 e 4,74 $\mathrm{mm}$ de diâmetro, enquanto que para o cultivar FT-10 utilizaram-se as peneiras de 7,25 e 5,0 mm. Para o cultivar FT-10, foram utilizadas as peneiras de 6,5 e $4,75 \mathrm{~mm}$. As sementes que atravessaram as peneiras superiores e ficaram retidas nas inferiores, foram submetidas a análise visual, para a retirada de todas as sementes danificadas (percevejo, umidade ou mecânico) e se constituíram no material utilizado na condução dos testes subseqüentes.

Para a determinação da qualidade inicial, as sementes dos três cultivares foram submetidas aos testes discriminados a seguir: teor de água das sementes (Brasil, 1992), germinação (Brasil, 1992), envelhecimento acelerado (Marcos Filho et al., 1987), condutividade elétrica (Vieira \& Krzyzanowski, 1999) e emergência de plântulas (Marcos Filho et al., 1987).

$\mathrm{Na}$ seqüência, objetivando causar diferentes tipos de danos mecânicos, 100 sementes de cada cultivar foram 
submetidas ao teste do pêndulo, o qual baseia-se na queda livre de um pêndulo metálico à uma altura de $13 \mathrm{~cm}$ sobre as sementes individualmente distribuídas em alvéolos de um disco metálico (Carbonell, 1991), o que corresponde a uma energia cinética aplicada sobre a semente, de 0,3185 joule.

Foram provocados danos mecânicos em seis regiões distintas das sementes (Figura 1), provocando-se o mesmo tipo de dano para cada região (A, B, C, D, E, F, ) em duas repetições de 50 sementes. A seguir, as sementes foram colocadas em placas com células individualizadas (numeradas), de maneira que pudessem ser identificadas nas determinações posteriores.

Para a detecção de danos externos, as sementes foram posicionadas de maneira a evidenciar os danos e fotografadas individualmente, utilizando-se uma câmera digital Nikon, modelo D1, acoplada a um computador Pentium III (600 MHZ, memória de 256 MB, HD Ultra SCSI de 20 GB e monitor de 21 polegadas).

Para a detecção dos danos mecânicos internos, as mesmas sementes (fotografadas anteriormente) foram submetidas ao teste de raios- $\mathrm{X}$, através da colocação de 100 sementes (duas repetições de 50) em alvéolos individualizados de uma placa acrílica, colocando-se por baixo uma fita adesiva transparente para fixar a semente em posição adequada. Devido à dificuldade de visualização do eixo embrionário nas radiografias (pouca diferença de contraste entre o eixo embrionário e os cotilédones), foram realizados testes de posicionamento da semente com relação à incidência dos raios-X e obteve-se melhores resultados quando o eixo embrionário ficou em ângulo de $45^{\circ}$ em relação à placa.

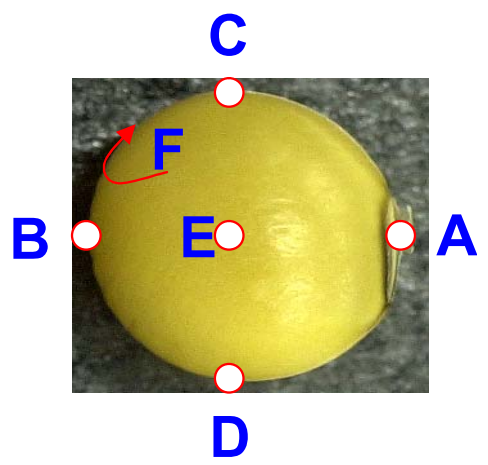

FIGURA 1. Foto da semente de soja, indicando os locais de impacto provocado pelo "teste do pêndulo": A: no hilo; B: na parte oposta ao hilo; C: na plúmula (parte superior da semente); $D$ : na parte oposta à plúmula; $\mathrm{E}$ : sobre o cotilédone esquerdo; $F$ : sobre o cotilédone direito.
Para a obtenção da radiografia, a placa de acrílico com as sementes foi colocada diretamente sobre um filme radiográfico (Kodak MIN-R 2000, tamanho de 18 × 24 $\mathrm{cm}$ ) à uma distância de $40 \mathrm{~cm}$ da fonte de radiação. $\mathrm{O}$ aparelho de raios-X utilizado foi o FAXITRON X-Ray, modelo MX-20.

O tempo de exposição e a intensidade de radiação que possibilitaram maior visualização de danos mecânicos internos em sementes de soja, foram determinados em ensaios preliminares, sendo os mais adequados a intensidade de $20 \mathrm{kV}$ e o tempo de exposição de 45 segundos.

Os filmes radiográficos foram revelados em uma processadora automática Hope X-Ray, modelo 319 Micromax. A seguir, as imagens dos filmes foram capturadas (uma a uma) por um Scanner Umax, modelo PowerLook 1100, para amplificação e melhor visualização no mesmo computador descrito anteriormente.

Com o intuito de avaliar os danos mecânicos detectados pela análise de imagens, as sementes de cada cultivar, previamente identificadas (numeradas) foram submetidas ao teste de germinação (Brasil, 1992), mediante a utilização de substrato de rolo de papel-toalha, umedecido com quantidade de água equivalente a 2,5 vezes o seu peso, em temperatura de $25^{\circ} \mathrm{C}$. As sementes foram semeadas em grupo de 10 (no terço superior do substrato, para permitir o desenvolvimento das plântulas de maneira individualizada). A interpretação foi efetuada aos 5 e 8 dias após a semeadura, de acordo com as Regras de Análise de Sementes (Brasil, 1992). Em seguida foram fotografadas individualmente todas as plântulas normais, anormais e as sementes não germinadas, utilizando-se a câmera digital acoplada ao computador. Desta maneira, todas as imagens puderam ser examinadas simultaneamente na tela do monitor, permitindo fazer um diagnóstico para cada uma delas.

Os danos mecânicos observados na análise externa e interna das sementes, receberam notas de acordo aos critérios descritos na Tabela 1, seguindo a classificação feita por Cícero et al. (1998) para sementes de milho e modificado para sementes de soja.

TABELA 1. Critérios utilizados para caracterizar as notas para os níveis de danos mecânicos observados no eixo embrionário e nos cotilédones das sementes de soja através das imagens de raios- $\mathrm{X}$

\begin{tabular}{lcc}
\hline .Nivel de dano & Eixo embrionário & Cotilédones \\
\hline Não observado & 1 & 1 \\
Não severo & 2 & 2 \\
Severo & 3 & 3 \\
\hline
\end{tabular}

Assim puderam ser avaliadas todas as imagens: análise visual da semente (morfologia externa), analise 
radiográfica (morfologia interna), com suas respectivas notas (níveis de dano) e plântula ou semente não germinada.

Os resultados foram analisados de forma comparativa, procurando-se relacionar os danos mecânicos detectados pela análise de imagens (semente por semente) com as possíveis anormalidades das plântulas e/ou sementes não germinadas. A análise estatística foi realizada em esquema fatorial $3 \times 7$ (três cultivares e sete regiões de dano nas sementes), com duas repetições de 50 sementes.

Os dados referentes aos testes para a determinação da qualidade inicial (germinação, envelhecimento acelerado e emergência de plântulas em campo) foram transformados em arc seno da raiz quadrada de $\mathrm{x} / 100$; os dados de condutividade elétrica não foram transformados. Esses testes foram submetidos à análise estatística com quatro repetições, utilizando-se o delineamento inteiramente casualizado. As medias foram comparadas pelo teste de Tukey com 5\% de probabilidade.

\section{RESULTADOS E DISCUSSÃO}

\section{Avaliação da qualidade inicial das sementes}

Os dados referentes ao grau de umidade das sementes (Tabela 2) foram semelhantes para os três cultivares estudados. Os testes de germinação, de envelhecimento acelerado, de emergência de plântulas e de condutividade elétrica (Tabela 2) indicaram que as sementes dos cultivares FT-2 e FT-10 apresentaram potencial fisiológico superior em relação ao cultivar IAC-2.

Avaliação de danos mecânicos pela análise de
imagens
O exame simultâneo das imagens das sementes

O exame simultâneo das imagens das sementes
e das plântulas e sementes mortas, provenientes do teste de germinação, permitiu proceder a um diagnóstico para cada caso estudado.

TABELA 2. Avaliação da qualidade inicial das sementes dos três cultivares estudados: grau de umidade (GU), teste de germinação (TG), condutividade elétrica (CE), envelhecimento acelerado (EA) e teste de emergência de plântulas (EP).

\begin{tabular}{cccccc}
\hline Cultivar & $\begin{array}{c}\text { GU } \\
(\%)\end{array}$ & $\begin{array}{c}\text { TG } \\
(\%)\end{array}$ & $\begin{array}{c}\text { CE } \\
\left(\mu \mathrm{mhos} \cdot \mathrm{cm}^{1} \cdot \mathrm{g}^{-1}\right)\end{array}$ & $\begin{array}{c}\text { EA } \\
(\%)\end{array}$ & $\begin{array}{c}\text { EP } \\
(\%)\end{array}$ \\
\hline FT-2 & $13,4 \mathrm{a}$ & $90 \mathrm{a}$ & $348 \mathrm{a}$ & $90 \mathrm{a}$ & $88 \mathrm{a}$ \\
FT-10 & $13,1 \mathrm{a}$ & $92 \mathrm{a}$ & $416 \mathrm{~b}$ & $88 \mathrm{a}$ & $90 \mathrm{a}$ \\
IAC-2 & $13,3 \mathrm{a}$ & $82 \mathrm{~b}$ & $524 \mathrm{c}$ & $80 \mathrm{~b}$ & $78 \mathrm{~b}$ \\
\hline CV $(\%)$ & 6,38 & 8,54 & 10,43 & 9,14 & 9,68 \\
\hline
\end{tabular}

$\mathrm{Na}$ coluna, médias seguidas da mesma letra não diferem entre si pelo teste de Tukey a $5 \%$ de probabilidade.
Na Tabela 3 são apresentados os resultados relativos aos danos observados nas imagens externas das sementes dos três cultivares. Assim, pode-se observar que o cultivar menos suscetível ao dano mecânico (FT-2) apresentou menores índices de danos severos (nota 3 ) e índices mais altos de sementes sem danos externos (nota 1) independentemente do local onde os danos foram provocados.

TABELA 3. Valores médios (\%) de sementes com diferentes intensidades de danos mecânicos, nos três cultivares estudados, avaliadas através da análise das imagens externas, nos diferentes locais onde os danos mecânicos foram provocados.

\begin{tabular}{ccccc}
\hline \multirow{2}{*}{ Local de Dano } & \multicolumn{3}{c}{ CULTIVAR } \\
\cline { 2 - 5 } & Nota & FT-2 & FT-10 & IAC-2 \\
\hline \multirow{3}{*}{ Hilo } & $1^{1}$ & $62 \mathrm{a}$ & $69 \mathrm{a}$ & $58 \mathrm{a}$ \\
& $2^{2}$ & $28 \mathrm{~b}$ & $20 \mathrm{~b}$ & $16 \mathrm{c}$ \\
& $3^{3}$ & $10 \mathrm{c}$ & $11 \mathrm{c}$ & $26 \mathrm{~b}$ \\
\hline \multirow{3}{*}{ Oposta ao hilo } & 1 & $56 \mathrm{a}$ & $48 \mathrm{a}$ & $49 \mathrm{a}$ \\
& 2 & $27 \mathrm{~b}$ & $26 \mathrm{~b}$ & $20 \mathrm{c}$ \\
& 3 & $17 \mathrm{c}$ & $26 \mathrm{~b}$ & $31 \mathrm{~b}$ \\
\hline \multirow{3}{*}{ Plúmula } & 1 & $74 \mathrm{a}$ & $76 \mathrm{a}$ & $52 \mathrm{a}$ \\
& 2 & $24 \mathrm{~b}$ & $21 \mathrm{~b}$ & $19 \mathrm{c}$ \\
Oposta à plúmula & 3 & $02 \mathrm{c}$ & $03 \mathrm{c}$ & $29 \mathrm{~b}$ \\
\hline \multirow{3}{*}{ Cotilédone esquerdo } & 1 & $75 \mathrm{a}$ & $69 \mathrm{a}$ & $54 \mathrm{a}$ \\
& 3 & $16 \mathrm{~b}$ & $15 \mathrm{~b}$ & $22 \mathrm{~b}$ \\
& 1 & $59 \mathrm{c}$ & $16 \mathrm{~b}$ & $24 \mathrm{~b}$ \\
\hline \multirow{3}{*}{ Cotilédone direito } & 2 & $50 \mathrm{~b}$ & $20 \mathrm{~b}$ & $28 \mathrm{~b}$ \\
& 3 & $07 \mathrm{c}$ & $22 \mathrm{~b}$ & $36 \mathrm{a}$ \\
\hline CV (\%) & 2 & $52 \mathrm{a}$ & $70 \mathrm{a}$ & $24 \mathrm{c}$ \\
& 3 & $08 \mathrm{c}$ & $22 \mathrm{~b}$ & $41 \mathrm{a}$ \\
& & 7,34 & 68,97 & $35 \mathrm{~b}$ \\
\hline
\end{tabular}

Médias seguidas da mesma letra, na coluna e para cada local de dano, não diferem entre si pelo teste de Tukey a 5\% de probabilidade.

${ }^{1}$ Dano não observado, ${ }^{2}$ Dano não severo, ${ }^{3}$ Dano severo.

No cultivar FT-10, as regiões danificadas no hilo, na plúmula e no cotilédone direito apresentaram comportamento semelhante, com valores de danos severos (nota 3) inferiores aos demais. Por outro lado, as sementes com danos provocados nas regiões oposta ao hilo, oposta à plúmula e no cotilédone esquerdo apresentaram danos severos e não severos semelhantes e inferiores aos danos não observados.

O cultivar IAC-2 (menor resistência ao dano mecânico) apresentou maior porcentagem de sementes com danos severos (nota 3) na região com danos mecânicos provocados no cotilédone esquerdo.

No presente trabalho, se fossem levados em conta apenas os exames das imagens externas das sementes, as 
imprecisões do diagnóstico seriam evidentes, pois dessa maneira seria possível apenas verificar danos no tegumento.

Por outro lado, a análise radiográfica foi realizada com o intuito de verificar a existência de possíveis danos internos nas sementes. Assim, utilizando os critérios para caracterizar os danos mecânicos presentes no eixo embrionário e nos cotilédones (Cícero et al., 1998), foram obtidos os dados contidos na Tabela 4. Desta forma, podese observar que, no cultivar FT-2, o eixo embrionário em todos os locais de dano, apresentou valores significativamente mais altos de sementes que não apresentaram nenhum dano interno (nota 1) quando comparados com as notas 2 e 3 (dano não severo e dano severo, respectivamente). Ainda, considerando o eixo embrionário, quando os danos foram provocados nos cotilédones esquerdo e direito, verificaram-se as menores porcentagens de sementes com danos severos e não severos, sendo que nesses casos, o efeito do impacto do pêndulo ficou mais restrito aos cotilédones. Quando são analisados os dados referentes aos danos observados nos cotilédones, observa-se que as sementes tiveram as menores porcentagens de danos severos independentemente dos locais onde os danos foram provocados. As regiões com maiores porcentagens de sementes que não apresentaram danos nos cotilédone (nota 1) foram as sementes com dano na plúmula e na região oposta à plúmula.

Por outro lado, no cultivar FT-10, quando foi avaliado o eixo embrionário, as sementes com danos no hilo, na plúmula, no cotilédone esquerdo e no cotilédone direito apresentaram comportamento semelhante com valores inferiores de danos severos (nota 3). Por outro lado, as sementes com dano na região oposta ao hilo tiveram porcentagem mais alta de danos não severos. Quando os danos foram provocados nos cotilédones esquerdo e direito, não houve manifestação de danos severos no eixo embrionário (nota 3 ) que, por sua vez, apresentaram maiores porcentagens de sementes sem dano (nota 1). Quando são observados os danos nos cotilédones para este mesmo cultivar (FT-10), todos os locais de dano apresentaram significativamente menores porcentagens de danos severos (nota 3).

No cultivar IAC-2, os resultados para a análise de danos no eixo embrionário indicam que maiores porcentagens de sementes sem danos (nota 1), em relação aos danos não severos e severos, foram obtidas em todos os locais onde os danos foram provocados. Por outro lado, menores índices de danos severos (nota 3) foram observados nas sementes com danos provocados no hilo, na plúmula, e na região oposta à plúmula. Nos cotilédones os valores mais altos de sementes sem dano (nota 1) foram obtidos nas sementes com danos provocados no hilo, na região oposta ao hilo, na plúmula e na região oposta à plúmula. Os danos severos (nota 3) foram mais expressivos nas sementes com danos nas regiões dos cotilédones esquerdo e direito.

De maneira geral, houve diferenças entre os danos (não observado, não severo e severo) independentemente do local onde o dano foi provocado, sendo que os danos provocados sobre os cotilédones esquerdo e direito proporcionaram menores porcentagens de danos severos. Tal comportamento pode ser explicado pelo fato dos danos provocados nos referidos locais não terem apresentado uma distribuição acentuada do dano na semente.

Assim, o teste de raios-X detectou danos internos não observados pela análise das imagens externas, concordando com vários autores que têm sugerido a utilização da análise de imagens digitais de raios-X para caracterizar e detectar danos internos em sementes (Cícero et al., 1998; Carvalho et al., 1999; Obando-Flor, 2000).

$\mathrm{Na}$ Tabela 5 encontram-se as médias de plântulas normais dos três cultivares, obtidas após a obtenção das imagens externas e internas das sementes. O exame da referida tabela permite verificar que a germinação das sementes dos cultivares estudados foi afetada pelos danos mecânicos. Observa-se que nos três cultivares existem diferenças entre os locais onde os danos foram provocados, sendo que as regiões sobre os cotilédones esquerdo e direito diferiram dos demais locais, observando-se maiores percentagens de plântulas normais. Por outro lado, não houve diferenças significativas entre os demais locais onde os danos foram provocados.

O cultivar IAC-2 foi afetado de maneira drástica, apresentando valores nulos para a maioria dos tratamentos. Da mesma maneira, quando se analisam as médias dos cultivares, observa-se que o cultivar FT-2 foi superior aos outros dois cultivares, ao passo que o cultivar FT-10 apresentou superioridade em relação ao cultivar IAC-2.

$\mathrm{O}$ teste do pêndulo mostrou-se muito drástico na danificação das sementes dos três cultivares, sendo que tal fato pode ser observado quando se compara às porcentagens de plântulas normais da testemunha com os dos demais tratamentos (Tabela 5). Quando os diferentes locais de danos nas sementes foram analisados, foi evidenciado que os danos provocados sobre os cotilédones esquerdo e direito, se mostraram mais resistentes comparativamente aos outros locais de dano, proporcionando as maiores porcentagens de plântulas normais (Tabela 5).

No presente trabalho observou-se que o cultivar FT2 foi o mais resistente ao dano mecânico, seguido do cultivar FT-10; o cultivar IAC-2 mostrou-se menos resistente. De acordo com os resultados obtidos no teste de germinação, pode-se classificar FT-2 como resistente, o FT-10 como medianamente resistente e o IAC-2 como menos resistente. Estes resultados concordam com a classificação feita por Alvarez (1994).

As Figuras 2 a 6 ilustram exemplos relativos aos três cultivares estudados. Na semente 48 do cultivar FT-10 
(Figura 2) na qual o dano foi provocado na região do hilo, foram constatados danos mecânicos externos severos (nota 3 ), apresentando o tegumento rachado e levantado (Figura 2A). A imagem de raios-X (Figura 2B), com nota $3 / 3$ (danos severos no eixo embrionário e nos cotilédones), por sua vez, acusou fraturas nos cotilédones e no eixo embrionário, entre a plúmula e o hipocótilo e na parte intermediária do hipocótilo, resultando em uma plântula anormal, com o hipocótilo desenvolvido, mas sem a raiz primária (Figura 2C).

Na semente 34 do cultivar IAC-2 (Figura 3), com o dano mecânico provocado na região oposta à plúmula, foi constatada uma rachadura externa no tegumento (Figura $3 \mathrm{~A}$ ), com nota 2. A análise radiográfica acusou dano severo, com nota $3 / 3$ (danos severos no eixo embrionário e nos cotilédones), mostrando as regiões do hipocótilo e a radícula separados (Figura 3B). Neste caso o dano mecânico ocorrido na parte oposta à plúmula estendeu-se até o eixo embrionário, resultando uma plântula anormal (Figura 3C).

TABELA 4. Valores médios (\%) de sementes com diferentes intensidades de danos mecânicos no eixo embrionário (EE) e nos cotilédones $(C)$, nos três cultivares estudados, avaliadas através da análise radiográfica, nos diferentes locais onde os danos mecânicos foram provocados.

\begin{tabular}{|c|c|c|c|c|c|c|c|}
\hline \multirow{2}{*}{$\begin{array}{l}\text { Local de } \\
\text { dano }\end{array}$} & \multirow[b]{2}{*}{ Nota } & \multicolumn{2}{|c|}{ FT-2 } & \multicolumn{2}{|c|}{ FT-10 } & \multicolumn{2}{|c|}{ IAC-2 } \\
\hline & & $\mathrm{EE}$ & $\mathrm{C}$ & $\mathrm{EE}$ & $\mathrm{C}$ & $\mathrm{EE}$ & $\mathrm{C}$ \\
\hline \multirow{3}{*}{ Hilo } & $1^{1}$ & $60 a$ & $47 \mathrm{a}$ & $49 a$ & $72 \mathrm{a}$ & $55 \mathrm{a}$ & $51 \mathrm{a}$ \\
\hline & $2^{2}$ & $14 \mathrm{c}$ & $40 \mathrm{~b}$ & $37 \mathrm{~b}$ & $26 \mathrm{~b}$ & $29 \mathrm{~b}$ & $22 b$ \\
\hline & $3^{3}$ & $26 \mathrm{~b}$ & $13 \mathrm{c}$ & $14 \mathrm{c}$ & $01 \mathrm{c}$ & $16 \mathrm{c}$ & $27 \mathrm{c}$ \\
\hline \multirow{3}{*}{$\begin{array}{l}\text { Oposta ao } \\
\text { hilo }\end{array}$} & 1 & $59 \mathrm{a}$ & $37 \mathrm{~b}$ & $32 \mathrm{~b}$ & $39 \mathrm{~b}$ & $40 \mathrm{a}$ & $43 \mathrm{a}$ \\
\hline & 2 & $24 \mathrm{~b}$ & $41 \mathrm{a}$ & $37 \mathrm{a}$ & $47 a$ & $29 \mathrm{~b}$ & $33 \mathrm{~b}$ \\
\hline & 3 & $17 \mathrm{c}$ & $22 \mathrm{c}$ & $31 \mathrm{~b}$ & $14 \mathrm{c}$ & $31 \mathrm{~b}$ & $24 \mathrm{c}$ \\
\hline \multirow[t]{3}{*}{ Plúmula } & 1 & $41 \mathrm{a}$ & $90 \mathrm{a}$ & $63 \mathrm{a}$ & $75 a$ & $39 a$ & $80 a$ \\
\hline & 2 & $36 \mathrm{~b}$ & $08 \mathrm{~b}$ & $27 \mathrm{~b}$ & $24 \mathrm{~b}$ & $35 \mathrm{~b}$ & $19 \mathrm{~b}$ \\
\hline & 3 & $23 \mathrm{c}$ & $02 \mathrm{c}$ & $10 \mathrm{c}$ & $01 \mathrm{c}$ & $26 \mathrm{c}$ & $01 \mathrm{c}$ \\
\hline \multirow{3}{*}{$\begin{array}{l}\text { Oposta à } \\
\text { plúmula }\end{array}$} & 1 & $55 \mathrm{a}$ & $90 \mathrm{a}$ & $45 \mathrm{a}$ & $83 \mathrm{a}$ & $49 \mathrm{a}$ & $70 a$ \\
\hline & 2 & $26 \mathrm{~b}$ & $10 \mathrm{~b}$ & $28 \mathrm{~b}$ & $14 \mathrm{~b}$ & $34 \mathrm{~b}$ & $27 \mathrm{~b}$ \\
\hline & 3 & $19 \mathrm{c}$ & $00 \mathrm{c}$ & $27 \mathrm{~b}$ & $03 \mathrm{c}$ & $17 \mathrm{c}$ & $03 \mathrm{c}$ \\
\hline \multirow{3}{*}{$\begin{array}{l}\text { Cotilédone } \\
\text { esquerdo }\end{array}$} & 1 & $91 \mathrm{a}$ & $27 \mathrm{~b}$ & $79 a$ & $35 \mathrm{~b}$ & $64 \mathrm{a}$ & $05 \mathrm{c}$ \\
\hline & 2 & $08 \mathrm{~b}$ & $69 a$ & $21 \mathrm{~b}$ & $58 \mathrm{a}$ & $18 \mathrm{~b}$ & $43 \mathrm{~b}$ \\
\hline & 3 & $01 \mathrm{c}$ & $04 \mathrm{c}$ & $00 \mathrm{c}$ & $07 \mathrm{c}$ & $18 \mathrm{~b}$ & $52 \mathrm{a}$ \\
\hline \multirow{3}{*}{$\begin{array}{l}\text { Cotilédone } \\
\text { direito }\end{array}$} & 1 & $91 \mathrm{a}$ & $25 \mathrm{~b}$ & $78 \mathrm{a}$ & $54 \mathrm{a}$ & $47 \mathrm{a}$ & $09 \mathrm{c}$ \\
\hline & 2 & $06 \mathrm{~b}$ & $74 \mathrm{a}$ & $22 b$ & $46 \mathrm{~b}$ & $28 \mathrm{~b}$ & $43 \mathrm{~b}$ \\
\hline & 3 & $03 \mathrm{~b}$ & $01 \mathrm{c}$ & $00 \mathrm{c}$ & $00 \mathrm{c}$ & $25 \mathrm{~b}$ & $48 \mathrm{a}$ \\
\hline CV (\%) & & 9,16 & 8,34 & 9,04 & 9,75 & 6,76 & 8,05 \\
\hline
\end{tabular}

Médias seguidas da mesma letra, na coluna e para cada local de dano, não diferem entre si pelo teste de Tukey a 5\% de probabilidade.

${ }^{1}$ Dano não observado, ${ }^{2}$ Dano não severo, ${ }^{3}$ Dano severo.
TABELA 5. Valores médios (\%) de plântulas normais dos três cultivares estudados, avaliadas através do teste de germinação, nos diferentes locais onde os danos foram provocados

\begin{tabular}{|c|c|c|c|c|}
\hline \multirow[t]{2}{*}{ Local de dano } & \multicolumn{3}{|c|}{ CULTIVAR } & \multirow{2}{*}{$\begin{array}{l}\text { Médias } \\
\text { do local } \\
\text { de dano }\end{array}$} \\
\hline & FT-2 & FT-10 & IAC-2 & \\
\hline Hilo & 19 a C & $12 \mathrm{~b} \mathrm{C}$ & $00 \mathrm{~b} \mathrm{C}$ & $10 \mathrm{C}$ \\
\hline Oposta ao hilo & 16 a C & $14 \mathrm{~b} \mathrm{C}$ & $00 \mathrm{c} \mathrm{C}$ & $10 \mathrm{C}$ \\
\hline Plúmula & 17 a $\mathrm{C}$ & 16 a C & $00 \mathrm{~b} \mathrm{C}$ & $11 \mathrm{C}$ \\
\hline Oposta à plúmula & 19 a C & 16 a C & $00 \mathrm{~b} \mathrm{C}$ & $12 \mathrm{C}$ \\
\hline Cotiléd. esquerdo & 32 a B & $26 \mathrm{~b} \mathrm{~B}$ & 02 c B & $20 \mathrm{~B}$ \\
\hline Cotiléd. direito & 36 a B & $24 \mathrm{~b} \mathrm{~B}$ & 04 c B & $21 \mathrm{~B}$ \\
\hline Testemunha & 84 a A & $78 \mathrm{~b} \mathrm{~A}$ & $77 \mathrm{~b} \mathrm{~A}$ & $80 \mathrm{~A}$ \\
\hline Médias & $32 \mathrm{a}$ & $26 \mathrm{~b}$ & $12 \mathrm{c}$ & - \\
\hline $\mathrm{CV}(\%)$ & 9,10 & 8,16 & 6,40 & 10,16 \\
\hline
\end{tabular}

Médias seguidas da mesma letra, minúscula na linha e maiúscula na coluna, não diferem entre si pelo teste de Tukey a $5 \%$ de probabilidade.

Na Figura 4 está apresentada a semente 16 do cultivar FT-2, a qual não sofreu dano mecânico (testemunha). A imagem externa (Figura 4A) mostra a semente sem nenhum dano (nota 1). A radiografia (Figura 4B) mostra o eixo embrionário bem diferenciado com notas 1/1 (sem danos no eixo embrionário e nos cotilédones), resultando em uma plântula normal (Figura 4C).

Na Figura 5, pode-se observar a semente 25, do cultivar FT-10 (testemunha), na qual não foram constatados danos mecânicos externos (Figura 5A), mas a imagem de raios-X (Figura 5B) indicou a existência de rugas na parte oposta ao hilo, constatando-se a presença de dano por umidade. A semente morta constatada no teste de germinação (Figura 5C) relacionou-se com o dano por umidade, observado na análise radiográfica. Observações feitas por França Neto et al. (1999) indicam que sementes com deterioração por umidade apresentam rugas características nos cotilédones, na região oposta ao hilo, ou sobre o eixo embrionário.

$\mathrm{Na}$ Figura 6 pode-se observar a semente 17 do cultivar IAC-2, com o dano mecânico provocado na região oposta ao hilo, onde foi constatado dano mecânico externo na sutura cotiledonar (Figura 6A). Entretanto, a imagem de raios-X não revelou dano mecânico interno, embora tenha detectado danos internos produzidos por percevejos (Figura 6B). Como conseqüência, houve morte da semente (Figura 6C). $\mathrm{O}$ ataque de percevejo proporciona lesões circulares características, muitas vezes enrugadas e profundas, podendo ocorrer lesões múltiplas numa única semente (França Neto et al., 1999). 
Desta maneira a radiografia permitiu observar sementes com danos mecânicos, danos por umidade e danos por percevejo, mostrados nas figuras $2,3,5$ e 6 . A literatura também indica que a radiografia das sementes permite a visualização de danos mecânicos, por insetos e decorrentes de outros fatores adversos de pré e póscolheita, na forma de rachaduras ou fraturas (ISTA, 1993; Poulsen et al., 1998).

Assim, a utilização da análise de imagens para a determinação de danos mecânicos, por umidade e por percevejo em sementes de soja, mostrou-se como uma eficiente alternativa em relação a outros métodos utilizados para o mesmo fim, com a vantagem de se poder comprovar os efeitos dos danos, por meio de testes fisiológicos, por tratar-se de método não destrutivo.

Estes resultados indicam que a análise de imagens constitui-se em mais uma ferramenta para avaliar a viabilidade e os danos mecânicos em sementes, podendo ser incluída nos programas de controle de qualidade das empresas produtoras de sementes de soja.
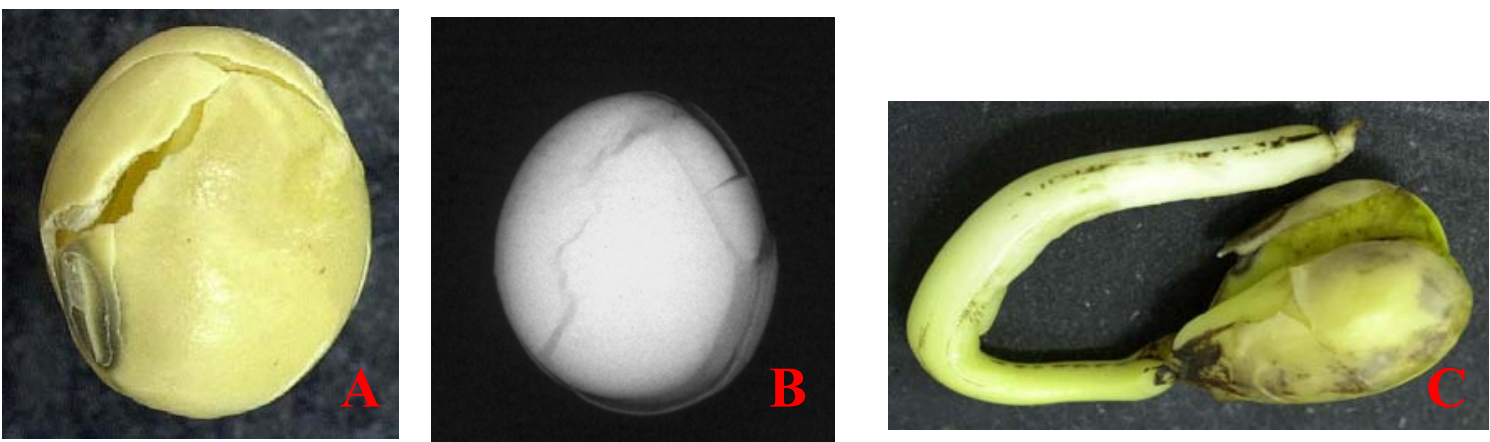

FIGURA 2. Cultivar FT-10, semente número 48 (dano provocado no hilo): imagem externa (A); radiografia (B) e plântula anormal (C).
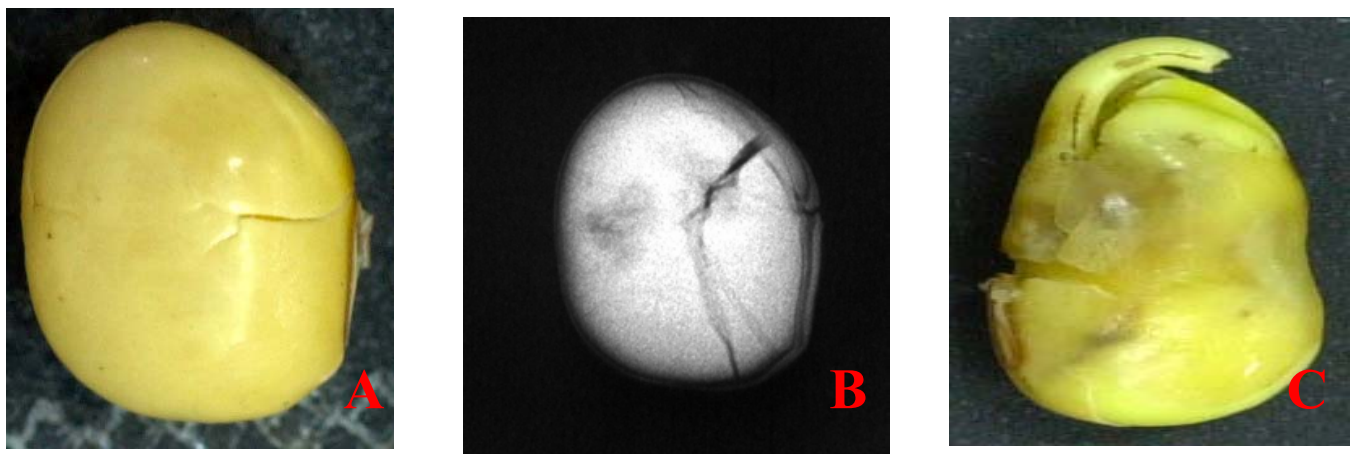

FIGURA 3. Cultivar IAC-2, semente número 34 (dano provocado na região oposta à plúmula): imagem externa (A); radiografia (B) e plântula anormal $(C)$.
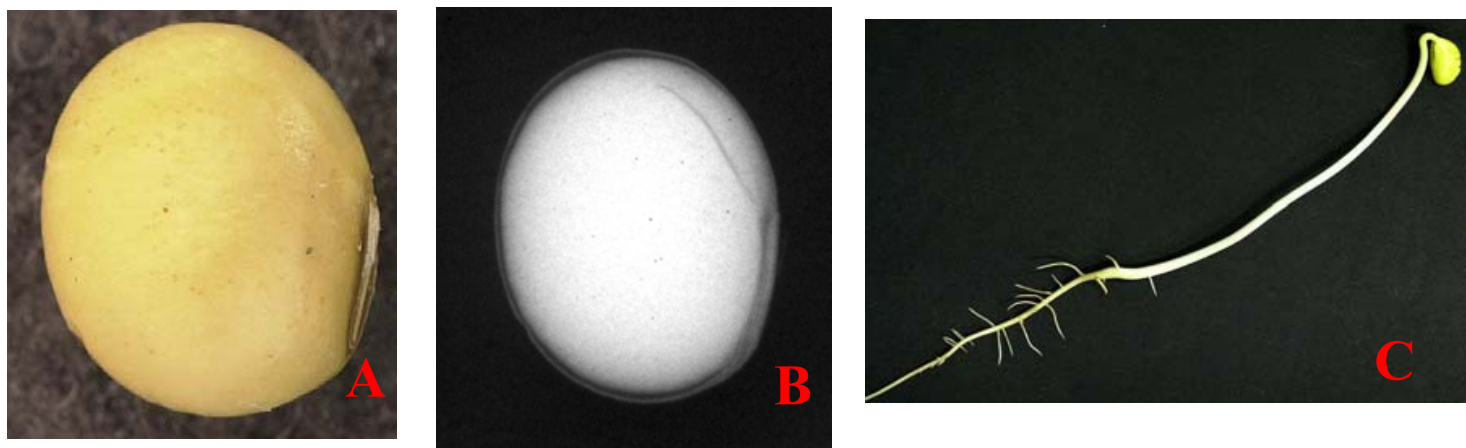

FIGURA 4. Cultivar FT-2, semente número 16 (testemunha): imagem externa (A); radiografia (B) e plântula normal (C). 

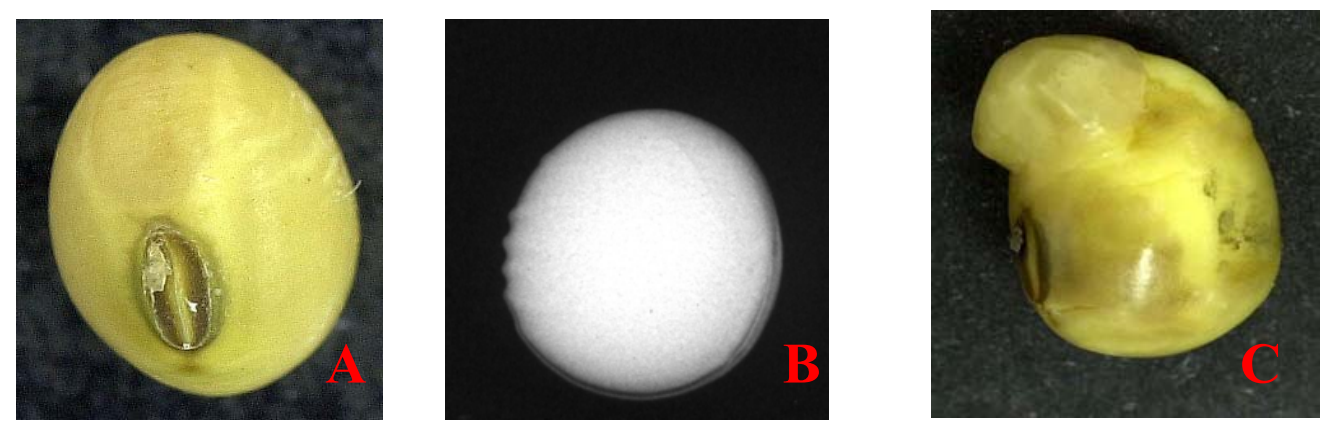

FIGURA 5. Cultivar FT-10, semente número 25 (testemunha): imagem externa (A); radiografia (B) e semente morta (C).
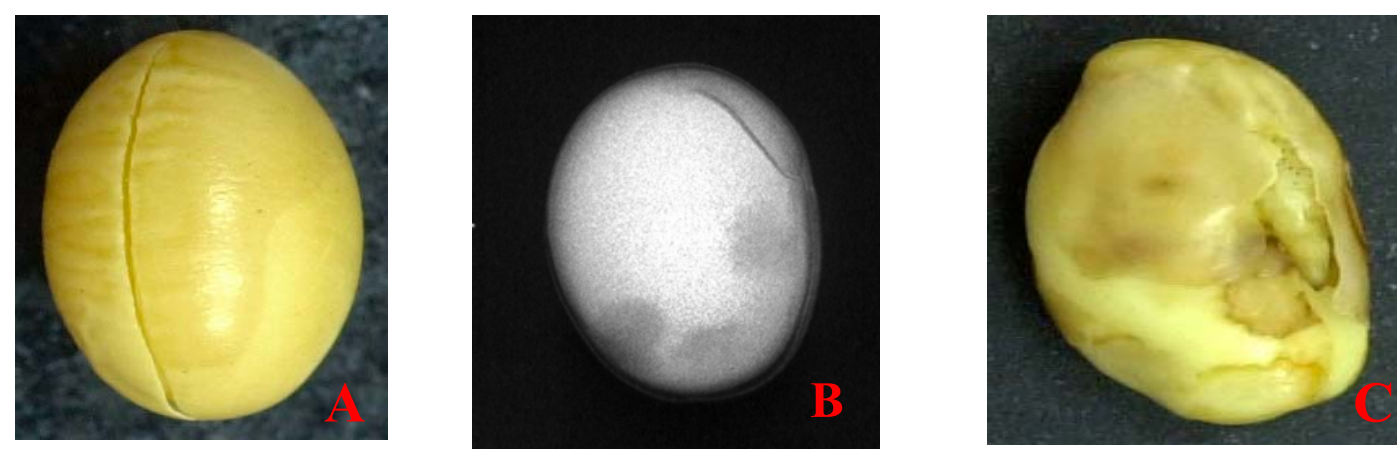

FIGURA 6. Cultivar IAC-2, semente número 17 (dano provocado na região oposta ao hilo): imagem externa (A); radiografia $(B)$ e semente morta $(C)$.

\section{CONCLUSÕES}

A análise de imagens permite identificar danos mecânicos externos e internos em sementes de soja; também, permite observar danos por umidade e danos por percevejo.

\section{REFERÊNCIAS}

ALVAREZ, P.J. Relação entre o conteúdo de lignina no tegumento de semente de soja e sua relação ao dano mecânico. Londrina. 1994. 43f. Dissertação (Mestrado em Agronomia). Universidade Estadual de Londrina, 1994.

BRASIL. Ministério da Agricultura e Reforma Agrária. Regras para Análise de Sementes. Brasilia: SNAD/DNDV/CLAV, 1992. 365p.

CARVALHO, M.L.M.; VAN AELST, A.C.; VAN ECK, J.W.; HOEKSTRA, F.A. Pre harvest stress cracks in maize (Zea mays L.) kernels as characterized by visual, X-ray and low temperature scanning electron microscopical analysis: effect on kernel quality. Seed Science Research, Wallingford, v.9, n.3, p.227-236, 1999.

CARVALHO, M.L.M; OBANDO-FLOR, E.P.; CABRAL, $P$. Internal damages of drying, evaluated by X-ray test and its effects on the quality of stored corn seeds (Zea mays L.). INTERNATIONAL SEED TESTING CONGRESSSEED SYMPOSIUM, 26 Angers. 18/20, jun. 2001. Abstracts... Angers: ISTA, 2001.p.73.

CARBONELL, S.A.M. Metodologia para seleção de genótipos de soja com semente resistente ao dano mecânico. Londrina. 1991. 103f. Dissertação (Mestrado em Agronomia), Universidade Estadual de Londrina, 1991.

CARBONELL, S.A.M.; KRZYZANOWSKI, F.C. The pendulum test for screening soybean genotypes for seeds resistant to mechanical damage. Seed Science and Technology, Zürich, v.23, n.2, p.331-339, 1995.

CÍCERO, S. M.; VAN DER HEIJDEN, G.W.A.M., VAN DER BURG W.J., BINO, R.J. Evaluation of mechanical damages in seeds of maize (Zea mays $\mathrm{L}$ ). by $\mathrm{X}$ ray and 
digital imaging. Seed Science and Technology, Zürich, v.26, n. p.603-612, 1998.

FRANÇA NETO, J. B.; HENNING, A.A. Qualidade fisiológica e sanitária de sementes de soja. Londrina: EMBRAPA - CNPSo, 1984. 39p. (Circular Técnica, 9).

GIRARDIN, P.; CHAVAGNAT, A.; BOCKSTALLER, C. Determination des charactéristiques des semences de mais grace a la radio graphie rayons $X$. Seed Science and Technology, Zürich, v.21, n. p.545-551, 1993.

INTERNATIONAL SEED TESTING ASSOCIATION. International rules for testing seed. Seed Science and Technology, Zürich, v.13, n.2, p.300-520, 1985.

INTERNATIONAL SEED TESTING ASSOCIATION. International rules for testing seed. Seed Science and Technology, Zürich, v.21, n. 363p., 1993. Supplement.

KAMRA, S.K. Determination of germinability of melon with X-ray contrast method. Proceedings of the International Seed Testing Association, Vollebekk, v.31, n.5, p.719-729, 1966.

LIU, Y.; VAN DER BURG, W. J.; AARTSE, J.W.; VAN ZWOL, R. A.; JALINK, H.; BINO, R. J. X-ray studies on changes in embryo and endosperm morphology during priming and imbibition of tomato seeds. Seed Science Research, Wallingford, v.3, p.171-178, 1997.

MACHADO, C.F. Metodologia para a condução do teste de germinação e utilização de raios-X para a avaliação da qualidade de sementes de aroeira-branca (Lithraea molleoides (Vell.) Engl.). Piracicaba. 2002. 51f. Dissertação (Mestrado em Fitotecnia). Escola Superior de Agricultura Luiz de Queiroz, 2002.

MARCOS FILHO, J.; CÍCERO, S.M.; SILVA, W.R. Avaliação da qualidade das sementes. Piracicaba: FEALQ, 1987.230p.

OBANDO-FLOR, E.P. Danos internos de secagem avaliados pelo teste de raios-X e seus efeitos na qualidade de sementes de milho (Zea mays L.) armazenadas. Lavras. 2000. 63f. Dissertação (Mestrado em Fitotecnia). Universidade Federal de Lavras, 2000.

OBANDO-FLOR, E.P.; CARVALHO, M.L.; COSTA, P.S.C. Utilização dos raios-X na avaliação da qualidade fisiológica em sementes de melão (Cucumis melo). In: CONGRESSO BRASILEIRO DE SEMENTES, 12, 2001. Anais... Curitiba: ABRATES, 2001. p.57.

OLIVEIRA, L.M. de. Avaliação da qualidade de sementes de canafístula (Peltophorum dubium (Sprengel) Taubert) pelos testes de germinação, tetrazólio e raios-X. Lavras 2000. 111f. Dissertação (Mestrado em Ciências Florestais). Universidade Federal de Lavras, 2000.

POULSEN, K.M.; PARRATT, M.J.; GOSLING, P.G. (Ed.) Tropical and subtropical tree and shrub seed handbook. Zurich: ISTA, 1998. 204p.

SAHLÉN, K.; BERGSTEN, U.; WIKLUND, K. Determination of viable and dead scots pine seeds of different anatomical maturity after freezing using the IDX method. Seed Science and Technology, Zürich, v.23, n.2, p.405-414, 1995.

SIMAK, M.; GUSTAFSSON, A. X-ray photography and sensitivity in forest tree species. Hereditas, Lund, v.39, p. 458-468, 1953.

SIMAK, M. A method for removal of filled-dead seeds from a sample of Pinus contorta. Seed Science and Technology, Zürich, v.12, n.3, p.767-775, 1984.

SMITH, A.J.; GRABE, D.F. Radiographic density measurements for determination of viability and vigour in corn (Zea mays) seeds. Seed Science and Technology, Zürich, v.13, n.3, p.759-768, 1985.

SWAMINATHAN, M.S.; KAMRA, S.K. X-Ray analysis of the anatomy and viability of seeds some economic plants. Indian Journal of Genetics and Plant Breeding, New Delhi, v.21, n.2, p.129-135, 1961.

VAN DER BURG, W. J.; AARTSE, J. W.; VAN ZWOL, R. A.; JALINK, H.; BINO, F. J. Predicting tomato seedling morphology by X-ray analysis of seeds. J. Amer. Soc. Hort. Sct., Alexandria, v.119, n.2, p.258-263, 1994.

VIEIRA, R.D.; KRZYZANOWSKI, F.C. Teste de condutividade elétrica. In: KRZYZANOWSKI, F.C.; VIEIRA, R.D.; FRANÇA NETO, J.B. (Ed.). Vigor de sementes: conceitos e testes. Londrina: ABRATES, 1999. p.1-26. 